\title{
К ВОПРОСУ О СТРУКТУРЕ АДМИНИСТРАТИВНОЙ ПРОЦЕДУРЫ В УКРАИНЕ
}

Маркова Е. О.

В научной cmamье автор проводит комплексное исследование внутренней структуры административной процедуры, состоящая из совокупности отдельных элементов: стадий, этапов и отдельных процедурных действий, осуществление которых определяется видом административной процедуры и логикой административно-процедурной деятельности. В отношении производства, автор в процессе исследования приходит к выводу о том, что производство является формой реализации административной процедуры. Значение стадий в характеристике административной процедуры заключается в том, что именно стадии отражают логическую последовательность развития соответствующего административного производства. Каждая стадия как структурный элемент состоит из процедурных этапов и действий, которые наполняют структуру процедуры функциональным содержанием. Таким образом, определённое количество последовательных процедурных действий, в зависимости от своего назначения, результата и других особенностей, объединяется в отдельные этапы, образующие соответствующие стадии, которые в своей совокупности и составляют содержание административной процедуры.

Ключевые слова: структура административной процедуры, административное производство, стадии, этапы и процедурные действия.

У науковій статmі автор проводить комплексне дослідження внутрішньої структури адміністративної процедури, що складається із сукупності окремих елементів: стадій, етапів і окремих процедурних дій, здійснення яких визначається видом адміністративної процедури й логікою адміністративно-процедурної діяльності. Щодо провадження, автор у процесі дослідження доходить висновку про mе, що провадження є формою реалізації адміністративної процедури. Значення стадій у характеристиці адміністративної процедури полягає в тому, що саме стадії відображають логічну послідовність розвитку відповідного адміністративного провадження. Кожна стадія як структурний елемент складається із процедурних етапів $і$ дій, які наповнюють структуру процедури функціональним змістом. Таким чином, певна кількість послідовних процедурних дій залежно від свого призначення, результату та інших особливостей об'єднується в окремі етапи, що утворюють відповідні стадії, які в своїй сукупності і становлять зміст адміністративної процедури.

Ключові слова: структура адміністративної процедури, адміністративне провадження, стадіі, етапи та процедурні діі.

Markova E. O. To the question of the structure of the administrative procedure in Ukraine

In this article, the author conducts a comprehensive study of the internal structure of an administrative procedure, which consists of a set of individual elements: stages, stages and individual procedural actions, the implementation of which is determined by the type of administrative procedure and the logic of administrative and procedural activities.

With regard to proceeding, the author in the process of research comes to the conclusion that proceeding is a form of implementation of an administrative procedure. Each stage as a structural element consists of procedural steps and actions that fill the structure of the procedure with functional content. Thus, a certain number of sequential procedural actions, depending on their purpose, result and other features, are combined into separate stages that form the corresponding stages, which, in their totality, constitute the content of the administrative procedure.

To highlight stages of the administrative procedure, the author uses the method of analogy of the norms of administrative procedural law.

Taking the proposed stages of the administrative process as a basis, the scientist Lazarev I.M. proposes to distinguish the following stages of the administrative procedure as: 1 . initiation of an administrative case and preliminary consideration of materials; 2 . consideration of the case on the merits by the competent authority (official) and the adoption of an individual legal act on this case; 3. appeal against the decision in the case (optional stage); 4. execution of the decision taken on the case (optional).

Using the "analogy" method, this system of stages is quite applicable to the administrative procedure, the second and third stages can be combined into one, since they are interrelated. Some authors distinguish additional stages from the composition of the first and second stages indicated above as independent ones.

Key words: structure of administrative procedure, administrative proceedings, stages, stages and procedural actions.

(С) Маркова Е. О., 2020 
Постановка проблемы и её актуальность. Административная процедура - это нормативно установленный унифицированный порядок, осуществления деятельности административным органом, направленный на ограничение административного усмотрения при реализации органом дискреционных полномочий в отношениях с гражданами, юридическими лицами в форме, установленной законом. Из определения можно выделить признаки, которые позволяют идентифицировать и отличить его от других понятий. Хотим обратить внимание на такой признак, как юридическая формализация, проявляющуюся в наличии определённых стадий реализации административной процедуры [1, с. 171]. Особенностью административно-процедурной деятельности является то, что, несмотря на специфику конкретных видов правоотношения, для достижения своих целей и задач соответствующий субъект власти в определённой последовательности осуществляет целый ряд процедурных действий. Таким образом, данная деятельность имеет чётко выраженный циклический характер (состоит из относительно замкнутых циклов). В.Б. Аверьянов отмечал, что каждое отдельное производство представляет собой определённое единство последовательно осуществляемых действий и процедур, направленных на рассмотрение и решение индивидуально-конкретных административных дел.

Целью статьи есть проведение комплексного исследования внутренней структуры административной процедуры, состоящей из совокупности отдельных элементов, осуществление которых определяется видом административной процедуры и логикой административно-процедурной деятельности.

Изложение основного материала. Из этого следует, что административная процедура характеризуется наличием внутренней структуры, состоящая из совокупности отдельных элементов: стадий, этапов и отдельных процедурных действий, осуществление которых определяется видом административной процедуры и логикой административно-процедурной деятельности.

Дополнительно к элементам административной процедуры Ю.А. Тихомиров относит [2, с. 125]: 1) процедурные правила, предназначенные для легального применения материально-компетенционных норм; 2) типичный набор юридический документов, принимаемых субъектами компетенции; 3) стадии и виды деятельности субъектов компетенции и связанных с ними других субъектов права, последовательность совершения юридических действий и их связь; 4) временная характери- стика (сроки, продолжительность, периодичность). Названные элементы опосредуются правом. По своей природе они являются организационно-функциональными правилами осуществления процедуры. Их юридический аспект выражен в операционном расчленении диспозиции материальной нормы и даже во ведении микрогипотез.

Рассматривая вопрос, касающийся структуры административной процедуры, украинский ученый-административист А.И. Николенко использовал критерии строения элементов и взаимосвязи между собой.

Первым и основным критерием элементов является наличие задач и целей, которые решаются и достигаются с помощью определенной группы процедурных действий. Такие задачи и цели бывают оперативные, тактические и стратегические. Вся совокупность процедурных действий, которые направлены на достижение стратегических заданий и целей, являются первым и основным элементом структуры административной процедуры.

Совокупность процедурных последовательных действий, которые направлены на достижение тактических заданий и целей, являются вторым элементом, который называется «стадией». Совокупность процедурных последовательных действий, которые направлены на достижение оперативных заданий и целей, является третьим элементом структуры под названием «этап». А вот четвертый элемент, с которого начинается процедура, является «процедурные действия».

Вторым важным критерием в построении структуры административной процедуры является составление документов и принятие актов, свидетельствующих о решении поставленных задач и достижении намеченных целей. Этот критерий является важным при определении стадий той или иной административной процедуры. Третий критерий - это круг участников процедуры и их правовые статус.

На сегодняшний день в административном праве не существует единого подхода к количеству и наименованию процедурных стадий административный процедуры, что затрудняет их содержательную характеристику.

В сложившиеся ситуации целесообразно обратится к работам отечественной и зарубежной доктрины, а также провести сравнительно-правовой анализ положений проектного украинского законодательства об административной процедуре и законодательства европейских стран (ФРГ, Польша) и США [7, с. 136].

В процессе проведения анализа приходим ко мнению, что и ученые, и авторы проектного зако- 
нодательства используют метод «аналогии» как универсальное средство преодоления (казуального восполнения) пробелов как в законодательстве, так и правоприменении. Аналогия во всех случаях допустима лишь тогда, когда данный вопрос прямо не урегулирован в законе и законодатель не связывает наступление юридических последствий только с конкретным законом, а соответствующий вопрос всё же находится в сфере права, требует юридического решения.

Следует согласиться с выводом, что «аналогия разрешена повсюду, где нет специального запрещения и где сам нормодатель не связывает наступление юридических последствий только с конкретным законом».

Вопрос о возможности применения аналогии, на наш взгляд, зависит от того, является ли аналогия применением права, или ее надлежит относить к области создания права. По мнению Ф. Регельсбергера, аналогия лежит на границе, но центр тяжести ее все-таки внутри сферы применения права, поскольку она опирается на положительное право и достигает своих результатов посредством оперирования определениями положительного права [4, с. 75].

Таким образом, посредством аналогии вырабатывается правоприменительное решение, которое по своей правовой сути нормой права не является. Здесь уместно привести позицию А.Б. Венгерова, который полагает, что применение аналогии закона или права «первоначально» приводит к выработке определенных правовых положений, которые затем могут в законодательном органе превращаться в нормы права». Между тем, сущность аналогии (как закона, так и права) заключается в направленности на устранение пробела в праве, то есть ситуации, когда определенные общественные отношения «выпадают» из сферы правового воздействия вследствие полного или частичного отсутствия «<..> правовых установлений (норм), необходимость которых обусловлена развитием социальной жизни и потребностями практического решения дел, основными принципами, политикой, смыслом и содержанием действующего законодательства, отвечающего правовым требованиям, а также иными проявлениями права, вытекающими из природы вещей и отношений».

Аналогия является только юридическим приемом, позволяющим лишь преодолеть, но не устранить пробел. Общая неурегулированность вопроса административной процедуры остается, но при помощи аналогии в данном случае она преодолевается. Со всей определенностью следует подчер- кнуть, что правоприменитель по общему правилу не уполномочен восполнять (устранять) пробелы [3, с. 24]. Он вынужден преодолевать это препятствие в решении дела, не будучи в силах его убрать.

Со стороны учёных метод аналогии во отношении административной процедуре применяется через разработанные наукой положений об административном процессе, а со стороны авторов проектного законодательства В.Б. Аверьянова и В.П. Тимощука - путём заимствования международного законодательного опыта. Анализируя представленные проектные документы - проект Административно-процедурного Кодекса и проект Закона «Об административной процедуре» - мы пришли к выводу о том, что первый документ подготовлен по аналогии немецкого Закона об административной процедуре, а второй - по аналогии польского Кодекса об административном производстве.

Предлагаем детально рассмотреть доктринально-законодательный подход, используя интегративный подход, который обеспечит эффективность в исследование данного вопроса.

Для того, чтобы понять, что представляет собой «структура административной процедуры», необходимо в первую очередь проанализировать ее элементы. Одним из фундаментальных элементов административной процедуры являются стадии, которые отражают ее упорядочивающий, последовательный характер, характеризующийся определенным набором субъектов, процедурных действий, охваченных единой юридической целью, и завершающийся определенным правовым результатом.

Значение стадий в характеристике административной процедуры заключается в том, что именно стадии отражают логическую последовательность развития соответствующего административного производства. Как отмечает Д. Бахрах, стадии следуют одна за другой, и каждая предыдущая подготавливает последующую: как правило, новая стадия может начаться лишь тогда, когда официально окончена ранее начатая [5, с. 608]. Кроме того, стадии не просто следуют одна за другой в каждой из них при определённых условиях может быть проведена проверка правильности деятельности в предыдущей [8, с. 401-402]. Каждой стадии свойственны свой специфичный состав субъектов правоотношений, собираемая и используемая информация, составляемые документы, принимаемые решения (промежуточные, окончательные) [5, с. 608].

Сейчас большинство современных ученых административного процесса определяют стадию как относительно обособленную, ограниченную 
временем и логично связанную совокупность процессуальных действий, направленных на достижение определенной цели и решение соответствующих задач конкретного административного производства, который характеризуется определенным кругом субъектов и закрепляется в процессуальных актах.

Каждая административная процедура, независимо от её конкретной разновидности, имеет ряд соответствующих стадий. Стадии отличаются друг от друга своими целями, задачами, кругом участников, спектром процессуальных действий, правовыми последствиями прохождения стадии и так далее. Анализ характерных особенностей административных процедур позволяет выделить в их структуре несколько основных стадий. Так, по мнению Д. Бахраха, целесообразное и законное использование властных полномочий допускает такую схему их реализации, при которой общими для любой административной процедуры являются стадии изучения и анализа фактической ситуации, подготовка и принятие обоснованного административного акта и исполнение решения (правового акта) (с. 608.) Также стадии административной процедуры делятся на обязательные и факультативные в зависимости от вида административной процедуры и от конкретных обстоятельств.

Каждая стадия как структурный элемент состоит из процедурных этапов и действий, которые наполняют структуру процедуры функциональным содержанием. Таким образом, определённое количество последовательных процедурных действий, в зависимости от своего назначения, результата и других особенностей, объединяется в отдельные этапы, образующие соответствующие стадии, которые, в своей совокупности, и составляют содержание административной процедуры.

Анализируя европейские модели административных процедур, выделяет следующие их «стадии» и «элементы»: публичные слушания, представление данных, консультации, обмен информацией, сбор доказательств, инструменты и механизмы разъяснения, согласования и принятия решения, обжалование, опротестование решения. Здесь речь идет, в первую очередь, о процедурных гарантиях прав невластных субъектов, условий принятия законных и обоснованных административных актов.

Прежде чем переходить к рассмотрению и анализу стадий административной процедуры, хотелось бы остановиться на некоторых ключевых понятиях, которые «содержательно наполняют» структуру административной процедуру и явля- ются ее основой: «административное дело» и «производство».

В научной доктрине «административное дело» раскрывается, в первую очередь, как отнесенный к компетенции публичной администрации вопрос, посредством разрешения которого органы государственного управления устанавливают права и обязанности невластных субъектов. К.В. Давыдов считает, что рассматривать понятие административное дело в рамках административной процедуры необходимо как управленческий бесконфликтный вопрос, разрешаемый публичной администрацией в рамках административной процедуры, создающий права и обязанности для его участников и отраженный в соответствующих материалах.

Например, в польской доктрине под понятием «административное дело» понимают конкретное жизненную ситуацию, которая регулируются положениями административного права. «Административное дело» предусматривает разрешение конкретной, индивидуальной ситуации в форме административного решения (например, выдача разрешения на строительство, оружие или выдача водительских прав).

Что касается понятия «производство», то оно широко применяется (но не поясняется) в законодательстве об административных правонарушениях (КоАП). Понятие «производства» в юридической литературе и в законодательстве употребляется в двух значениях:

- для характеристики определенной юридической деятельности, подчеркивая особенность процедурной (процессуальной) формы (например, «апелляционное производство», «кассационное производство и так потом);

- для характеристики большого массива последовательных действий, объединенных единой целью. На это обратила внимание и И.В. Панова при характеристике юрисдикционных производств [6, с. 116-118].

Однако А.И. Николенко считает, что производство необходимо рассматривать как элемент структуры юридической процедуры. В связи с этим производство нужно рассматривать как совокупность последовательных действий, объединенных конкретной целью, которые осуществляются субъектом властных по рассмотрению и решению административного дела.

В проектном законодательстве «Об административной процедуре» производство определяется как совокупность процедурных действий, последовательно совершенных административным орга- 
ном, и принятых процедурных решений по рассмотрению и решения административного дела, что завершается принятием и, в необходимых случаях, выполнением принятого административного акта. Мы считаем, что сформулированное определение является достаточно полным с учетом специфики процедурной сферы.

Теперь перейдем непосредственно к анализу стадий административной процедуры, используя как отечественные наработки, так и доктринально-законодательный опыт зарубежных стран, в частности ФРГ, Польши, США.

В научной и учебной литературе выделяют следующие «классические» общие стадии административного процесса:

1) возбуждение производства по административному делу;

2) рассмотрение административного дела;

3) принятие решения по административному делу;

4) исполнение решения по административному делу;

5) пересмотр решения по административному делу .

Принимая за основу предложенные стадии административного процесса, ученый И.М. Лазарев предлагает выделить следующие стадии административной процедуры: 1. возбуждение административного дела и предварительное рассмотрение материалов; 2. рассмотрение дела по существу компетентным органом (должностным лицом) и принятие по этому делу индивидуального правового акта; 3. обжалование решения по делу (факультативная стадия); 4. исполнение принятого по делу решения (факультативная).

Используя метод «аналогии», данная система стадий вполне применима к административной процедуре, вторую и третью стадию можно объединить в одну, поскольку они взаимосвязаны. Некоторые авторы выделяют из состава первой и второй указанных выше стадий в качестве самостоятельных дополнительные стадии, как, например, В.А. Лория, А.П. Коренев [8, с. 75].

Выводы. Анализируя положения украинского проектного законодательства об административных процедурах на предмет закрепления стадий административной процедуры, мы пришли к выводу, что в них они представлены достаточно структурировано и содержательно, особенно в проекте Административно-процедурного Кодекса. Выделяем следующие стадии:
Правове забезпечення адміністративної реформи

1) Инициирование (возбуждение) административного производства (Глава 1, 2);

2) Начало административного производства и подготовка дела к рассмотрению (Глава 2);

3) Рассмотрение дела и принятие решения (Глава 3);

4) Обжалование (Глава 6).

Каждая стадия административной процедуры предусматривает осуществление в соответствии с настоящим Кодексом процедурных действий и принятия решений, которыми обеспечивается принятие административного акта и его выполнение.

\section{Литература}

1. Дмитриев Ю.А. Административное право Российской Федерации : учебник / Ю.А. Дмитриев, И.А. Полянский, Е.В. Трофимов. Москва : Система ГАРАНТ, 2008. 587 С.

2. Административные процедуры и контроль в сете европейского опыта под редакцией Т.Я. Хабриевой Ж. Марку. Москва : Стату, 2011. С. 320.

3. Дёмин А.В. Аналогия закона и аналогия права как универсальные методы восполнения пробелов в налоговом праве. Научный вестник Омской академии МВД России. № 4(47). 2012. С. 23-27.

4. Регельсбергер Ф. Общее учение о праве / под ред. Ю.С. Гамбарова. Москва, 1897. С. 170.

5. Бахрах Д.Н. Административное право : учебник / Д.Н. Бахрах, Б.В. Россинский, Ю.Н. Старилов. 3-е изд., пересмотр. и доп. Москва : Норма, 2007. 816 с.

6. Теория государства и права : курс лекций / под ред. Н.И. Матузова, А.В. Малько. Москва : Юристъ, 1999. 672 с.

7. Schmidt-Assmann E. Structures and Functions of Administrative Procedures in German, European and International Law, in Transforming Administrative Procedure, Barnes J. (ed), Sevilla, 2008. Р. 49.

8. Лория В.А. Проблемы кодификации советского административно-процессуального права, автореф. дис. ... д.ю.н. Киев, 1976. С. 13, С. 45-46.

9. Коренев А.П. Административное право России. Москва, 2000. С. 244-245.

Маркова Е. О., кандидат юридических наук, доцент, доцент кафедры юридических дисциплин

Сумского филиала Харьковского национального университета внутренних дел 